\title{
Study on the Design of Enterprise Comprehensive Information Management System
}

\author{
Wang Dan \\ Jiangxi College Of Foreign Studies
}

\begin{abstract}
In recent years, with the constant development of computer technology and communication technology, effective management of information resources has become increasingly important for enterprises. The decision-makers should master the development situations of market timely and accurately as well as internal operation situations and other related information with rapid, comprehensive and deep analysis on these information so as to make correct decisions by understanding market orientations and evaluating risks. By establishing comprehensive information system, enterprises can improve their inside situations for information communication, which can help to improve the modernization level of decision-making and management with better competitiveness. Besides, design of an effective and comprehensive information system requires detailed thinking, planning and coordination by developers and administrators. In this paper, exploration and study have been conducted on the comprehensive information system from the perspectives of technology and application.
\end{abstract}

Keywords-management information system; information management; design of database

\section{INTRODUCTION}

Since the 1990s, construction of enterprise informatization and information system has always been a major subject in China. From the angle of information processing, production and operation of an enterprise is a process of data processing fundamentally. The whole process of data production, collection, arrangement, transmission and reception is actually a process of production, collaboration and communication among workers. The major task that information system faces is how to realize the automation of data processing. The effect of information has become more and more important, which has become a strategic resource for the economic growth. Information technology will become a core technology promoting economic development and social progress. Thus, enterprises will inevitably enter an age of information and network. It will become necessary means for enterprises to achieve competitive advantages by establishing comprehensive information management system.

Through management on basic statistic information, analysis of large statistics, economic prediction and analysis of distributed ER integrated management information system, the paper has discovered that enterprise comprehensive information management system should be a platform for enterprises' infrastructure and application with a core position in enterprises' information construction as the data center and knowledge center. In order to guarantee the extendibility and scalability of the system, a four-level application structure of original data level, data store level, application logic level and display level should be adopted by the system. 


\section{DEVELOPMENT METHODS OF ENTERPRISE} COMPREHENSIVE INFORMATION MANAGEMENT SYSTEM

The management information system is a man-machine system, so it needs to be developed by systematic rules from the perspective of system. First in this chapter, typical methods of developing information system as well as realization technologies are introduced with the proposal of development strategies as well as proper development methods.
The traditional system life circle approach is shown below in Fig .1 which is a trial from software development to engineering. It divides a development process into several stages and each stage has a evaluation scale for its work performance. Life circle approach carries out work step by step strictly. The result in the former stage is right the basis for the work in the later stage.

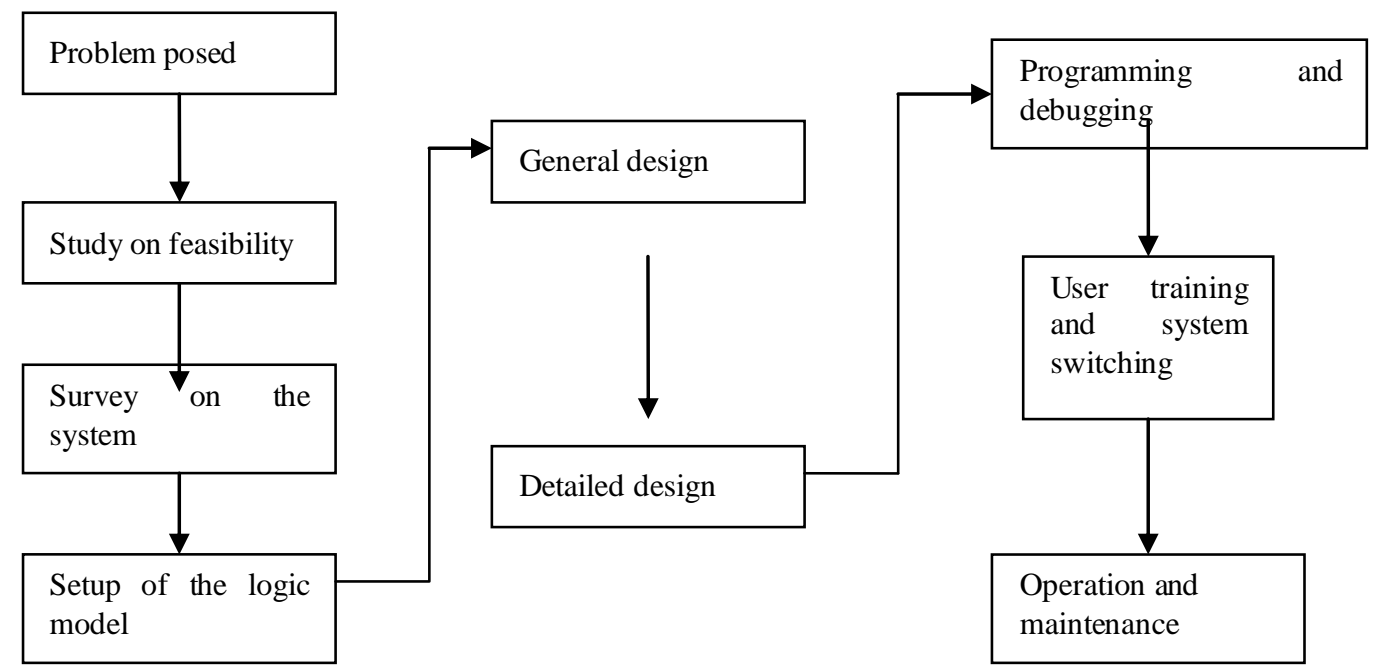

Figure 1. Basic steps of life circle approach

During the development, since the developers have little knowledge of the system information with incomplete description of the logic model of the system, problems usually expose in the middle stage of the development, which may lead to incomplete, unreliable and even a failed system. Thus, during the development, review and acceptance are especially important with timely adjustment. Only if the former job is satisfied, we can go on to the next stage.

\section{THE DESIGN IDEAS OF ENTERPRISE COMPREHENSIVE}

\section{INFORMATION MANAGEMENT SYSTEM}

The concept of facility application has been proposed based on the analysis of basic statistic information management, large statistics, economic prediction and distributed ER integrated management information system and so on. The enterprise comprehensive information management system should become an enterprise' infrastructure and application platform with a core position in enterprise's informatization construction as data center and knowledge center. Two big goals of facility application should be reached.

The automation of data processing means to offer complete support for the processing of statistic data, which is a process and section involving data collection, review, transmission, reception, sorting, summary, storage and application. In the whole process, the accuracy, completeness, consistence and timeliness of statistic data should be ensured to provide basic conditions for the further deeper processing of statistic data.

Support of data usefulness. Statistic data may have no significance without being used. The facility application should offer common tools for data access and analysis, such as tools for comprehensive inquiry and statistic expectation as well as expert system so that users can know about their situation rapidly with deeper 
understanding of information. On the other hand, facility application has open and extensive structure, which allows new functional modules to be fast introduced so that new applications can be connected with it conveniently.

\section{SAFE DESIGN OF ENTERPRISE COMPREHENSIVE}

\section{INFORMATION MANAGEMENT SYSTEM}

The safe design of system mainly refers to the safety of application system; however, when designing the safety of application system, safety features of communication and database have also been considered, including identity authentication, communication encryption, user authorization management and log management. Communication encryption is built on the SSL technology to avoid illegal tamper and access to data during transmission.

Authority management includes management on all resources, such as functions, units, indicators, statements, query template and cubes and so on.

\section{A. User management}

The user management is the foundation of authority management. It requires to conduct grouping management on users including user groups and users. User groups, as the container, are used to hold users. One user can belong to many user groups, but user groups have no affiliation relations to each other.

\section{B. Function privilege}

The management of function privilege divides users into different groups by different functions. The divided functional modules include data inquiry, data entry, data auditing, data report, statement analysis, comprehensive analysis and system maintenance.

\section{Unit permission}

Authorization of data access by unit can divide the access limits of data by different levels. Users of different levels have different permissions to data access. The upper units have the access to all reported data from lower units with right to designate which to be read and which to be written down. The lower units can have access to data of upper units as well as related analyzed data by applying rights from administrator.

\section{Data permission}

The function of data permission can authorize the user by indicator, indicator groups, statement and inquiry template and so on. The authorized party has access to data in a certain range.

\section{V.CONCLUSION}

Based on the analysis of current enterprise information system and future application demand, development methods for a comprehensive information system have been determined in this paper. Through management on basic statistic information, analysis of large statistics, economic prediction and analysis of distributed ER integrated management information system, the paper has discovered that enterprise comprehensive information management system should be a platform for enterprises' infrastructure and application with a core position in enterprises' information construction as the data center and knowledge center. In order to guarantee the extendibility and scalability of the system, a four-level application structure of original data level, data store level, application logic level and display level is adopted by the system. When designing the safety of application system, safety features of communication and database have also been considered, including identity authentication, communication encryption, user authorization management and log management.

\section{REFERENCES}

[1] Whittaker S, Sidner C. Email Overload: Exploring Personal Information Management of Email.[C]// Sigchi Conference on Human Factors in Computing Systems. 1996:276-283.

[2] Franklin M, Halevy A, Maier D. From databases to dataspaces: A new abstraction for information management[C]// SIGMOD Record. 2005:27--33.

[3] Heimbigner D, Mcleod D. A federated architecture for information management[J]. Acm Transactions on Information Systems, 1985, 3(3):253-278.

[4] Berners-Lee T J. Information management: a proposal[J]. Cern Cern, 1989.

[5] Madden K G. Information Management for the Intelligent Organization: the Art of Scanning the Environment.[J]. Journal of the American Society for Information Science, 1996, 47(7):795-796A

[6] Sezan I M, Qian R, Van Beek P J L. Audiovisual information management system: US, US8028314 B1[P]. 2011.

[7] Sezan I M, Qian R, Van Beek P J L. Audiovisual information management system: US, US8028314 B1[P]. 2011.

[8] Ito, Naoko, and K. Takeda. "Information management technique." US, US20040199550 A1. 2004.

[9] Claudatos C H, Andruss W D. Efficient information management: US, US20060004818[P]. 2006 
[10] Davison - Turley, Whitney. "Blogs and RSS: Powerful Information Management Tools." Library Hi Tech News volume 22.10(1999):28-29(2).

[11] Bergman O, Beyth\&\#x;Marom, Ruth, Nachmias R. The user subjective approach to personal information management systems design: Evidence and implementations[J]. Journal of the American Society for Information Science \& Technology, 2008, 59(2):235-246

[12] Bergsjö D, Malvius D. Use of Information Management Systems from Designers' Perspective[J]. Machine Design, 2006. 